\title{
Endoscopic treatment of tracheoesophageal fistula
}

\author{
Gursu Kiyan^ \\ Department of Pediatric Surgery, Marmara University School of Medicine, Istanbul, Turkey \\ Correspondence to: Gursu Kiyan. Department of Pediatric Surgery, Marmara University School of Medicine, Istanbul, Turkey. Email: \\ gursukiyan@marmara.edu.tr.
}

\begin{abstract}
Surgical treatment (ST) is the classical method of treatment of both congenital and recurrent tracheoesophageal fistula (RTEF). On the other hand, endoscopic treatment (ET) of RTEF has been reported with an increased frequency in the literature. This method of treatment consists of either deepithelialization of the tract of the fistula or glue application to the fistula, almost always from the tracheal side and using a ventilating rigid bronchoscope. For these procedures different equipments and materials are used in the literature and they are performed either alone or in combination. Even though ET of RTEF was reported frequently in the last two decades, a standard method of this option has not been constituted yet. Although ET is reported to be used for all types of tracheoesophageal fistula (TEF) in different reports, its use is rather accepted in cases with RTEF. ET is an easy, less expensive and less invasive method and has low complication rates when compared to ST. It can be repeated easily and does not have any adverse effect for any necessary ST in this area. Main disadvantages of this method are its high recurrence rate and prolonged period of aspiration because of recurrences and repeated attempts of endoscopic closure. In conclusion, ET is a promising alternative method for the management of RTEF, with an increased popularity. Thus, it can be performed as the first line therapy of the RTEF. Patients with failed endoscopic management should be managed surgically immediately.
\end{abstract}

Keywords: Treatment; endoscopy; tracheoesophageal fistula (TEF); recurrent

Received: 08 February 2021; Accepted: 16 March 2021; Published: 25 August 2022.

doi: $10.21037 /$ ccts-21-7

View this article at: http://dx.doi.org/10.21037/ccts-21-7

Tracheoesophageal fistula (TEF) is either congenital or recurrent after a previous TEF repair or iatrogenic after different types of trauma. Recurrent tracheoesophageal fistula (RTEF) is a complication of TEF repair, which is most frequently a component of the surgical treatment (ST) of esophageal atresia (EA) with TEF. RTEF is reported to be between $4.4 \%$ and $8 \%$ of patients after EA with TEF repair in large series $(1,2)$. Thoracoscopic repair of EA with TEF has gained popularity in the last decade and Iacona $e t$ al. reported a recurrence rate of $5.3 \%$ in their review of the literature of thoracoscopic repair of EA with distal TEF (3).

Recurrent TEF may cause feeding problems and respiratory problems due to aspiration. Thus, RTEF can be detected by radiological or endoscopic methods during assessment of these problems. On the other hand, in some asymptomatic patients TEF can be detected during routine evaluation. Bruch et al. reported a diagnostic period of 2.1 months postoperatively in 24 patients, if two patients in their series, who have periods of five and 18 years, were excluded (2). Since the fistula does not close spontaneously, an intervention is required for management of RTEF. The conventional method for these patients is ST. The most common approach among these surgical techniques is open thoracotomy, which bears significant technical difficulties in the previously operated areas, has a high rate of morbidity, and may occasionally cause death. The hospital stay is long and patient discomfort is noteworthy, if ST is performed. The recurrence rate after surgical closure of a RTEF is

\footnotetext{
^ ORCID: 0000-0001-5461-353X.
} 

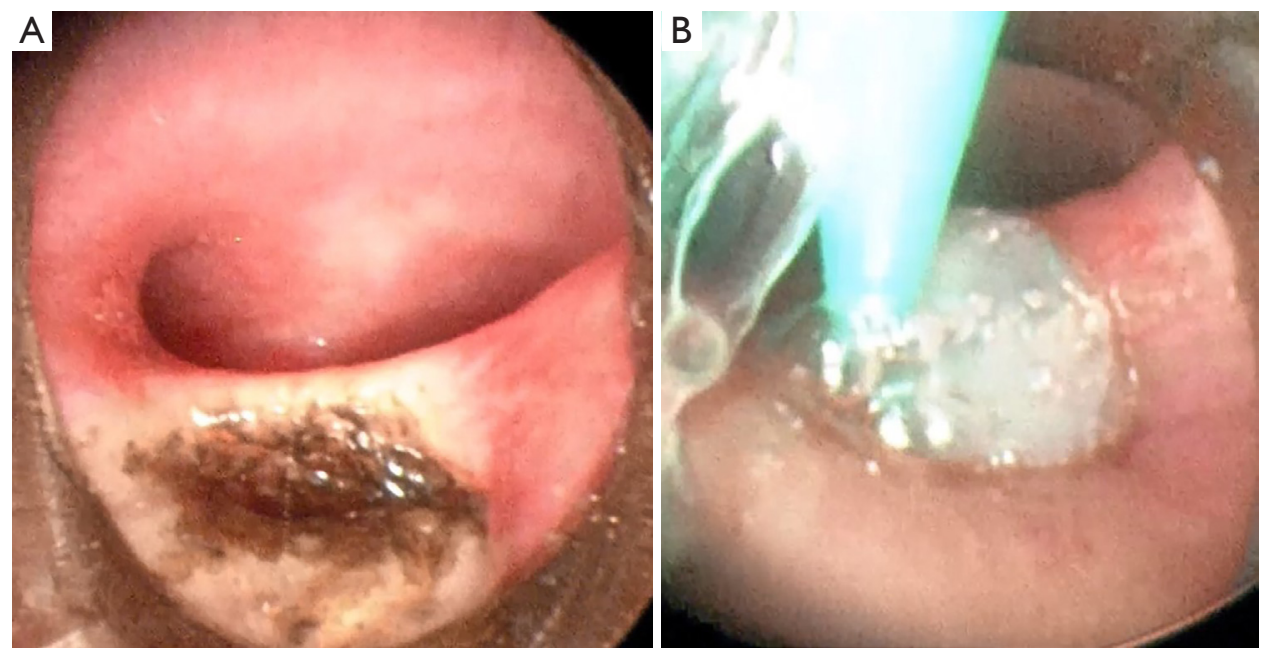

Figure 1 Bronchoscopic views of laser fulguration combined with fibrin glue application. (A) Appearance of the fistula after laser fulguration; (B) fibrin glue application to the fistula.

even higher $(1,2,4)$, which makes the problem even more difficult.

Although not the standard method of treatment, after the first report by Gdanietz et al. (5) in 1974, endoscopic approach for management of RTEF has gained increased popularity and many case reports, case series and reviews are published in the literature thereafter. These reports propose different techniques for endoscopic closure of the fistula mostly from tracheal but rarely from esophageal side.

Main advantage of endoscopic treatment (ET) is that it is less invasive and therefore can be better tolerated by the patients. It can be performed as outpatient surgery, can be repeated easily, is less costly, and does not invalidate if further ST is required. On the other hand, the success rate of ET is lower than that of ST.

The intervention is carried out by a rigid ventilating bronchoscope using telescopic magnification. Techniques used for closure of RTEF can be categorized as deepithelialization of the fistula, adhesive application or a combination of both of these techniques $(6,7)$. Besides these frequently used methods, there are other techniques described in the literature as well.

Adhesives that are used to glue the walls of the fistula together are fibrin glue and n-butyl cyanoacrylate. Fibrin glue is the preferred material of adhesive in many studies in the literature (8-14). It is a biologic product which creates fibrin clot, and this clot provides haemostasis and sealing (Figure $1 A, 1 B$ ). It enhances formation of granulation tissue and leads to early epithelialization (15). Some centers prefer adding aprotinin, which is an antifibrinolytic agent, to fibrin glue (7). The other material used to glue the fistula is n-buthyl-z-cyanoacrylate $(5,16-18)$. Cyanoacrylates obliterate fistulae by rapid solidification and stimulates inflammatory response, which provoke granuloma formation and epithelialization (19). In the review of Lal and Oldham (20) the overall success rates of n-buthyl-zcyanoacrylate only use and fibrin glue only use are $62 \%$ and $67 \%$, respectively.

De-epithelialization, on the other hand, was provided by diathermy $(7,10,12,14,16,21,22)$, different type of lasers $(22,23)$, argon plasma coagulator (21), mechanical abrasion with brush (8) or forceps (24), and chemocauterization with trichloroacetic acid (TCA) $(25,26)$ in different papers. In all these techniques, epithelial lining of the fistula was destroyed in order to provide an easy coaptation of both walls of the fistula.

If the literature regarding ET for TEF repair is reviewed, to make some conclusions for this relatively new method, certain obstacles were observed. The main limitation in reviewing the literature is its heterogeneity. Centers used different techniques or equipments for ET. Authors mostly tend to publish their case reports or small case series if the outcomes are positive. Case series generally contain small number of patients, there are no large series with sufficient number of patients and high level of evidences. The number of ET sessions before converting to ST varies as well. And finally follow-up periods also vary, especially in case reports.

In this paper, for the overview of the topic, reviews of the 
literature are evaluated first. The most recent review of the literature is published in 2017 but it only includes reports on electrocauterization (EC) of the fistula (21). Authors reviewed 32 patients with RTEF (33 fistulae) treated by EC. Success rates in patients treated with endoscopic EC alone or treated by combination with an adhesive or laser were $67 \%$ and $86 \%$, respectively. The overall success rate was $78.8 \%$ after a mean of 1.88 sessions. Gregory et al. further emphasized in this review, that EC causes minimal morbidity and complications reported are from early reports which may have used the cautery aggressively (22). At the end of their review, authors concluded that ET is a safe and successful method in management of RTEF.

In an earlier review, in 2014, Aworanti and Awadalla went over a total of 44 papers and 165 patients either treated by ET or ST. They reported a success rate of $84 \%$ for ET and of $93.5 \%$ for ST (6). All failed ET cases were successfully treated afterwards by ST. They evaluated the literature by dividing the patients into three groups. In group 1, patients were managed by de-epithelialization only. There were 15 patients and overall success rate was $87 \%$ after an average of 2.7 sessions. In the sealent only group, there were only 6 patients and the overall success rate was $84 \%$ after an average of 1.5 sessions. Largest group was combination group which consisted of 36 patients and in this group in $83,4 \%$ of patients the treatment was successful after an average of 2 sessions. In this review they reported three papers describing significant complications following ET $(22,27)$. Aworanti and Awadalla found only one paper reporting a case of death and the reason of this death which occurred 3 days after the procedure was not notified (16). Finally, Aworanti and Awadalla concluded that ET is an alternative method for selected cases in experienced centers, but ST is still the treatment of choice for RTEF.

In an earlier review of the literature by Richter $e t$ al. in 2008, overall success rates for sealent only group, deepithelialization only group, and combination group, were $78.6 \%, 62.5 \%$ and $93.3 \%$, respectively (7). Overall success rate was $81.1 \%$, while this rate was $48.6 \%$ after the first session. In this paper, based on their experience with four patients managed by diathermy and fibrin glue, authors concluded that proximal and narrow fistulae with a diagonal tract are the better candidates. Authors also proposed intubation and ventilation of the patient with a cuffed tube beyond the fistula for 48 hours postoperatively.

In another review by Meier et al. in 2007 (8), 62 patients of ET in the literature were evaluated and an overall success rate of $60 \%$ after an average of 2.1 sessions was detected.
They compared the success rates of fibrin glue and tissue adhesives and found them to be $55 \%$ and $48 \%$, respectively. Among patients in tissue adhesive group, in five patients a sclerosing agent was additionally applied and the success rate in this small group was $100 \%$. They managed three patients with de-epithelialization and fibrin glue with a success rate of $66 \%$. They finally concluded that ET is a safe and effective alternative and they recommend using fibrin glue for obliteration after abrading the fistula using a bronchial brush.

In contrast to several advantages of ET, one of the essential disadvantages of ET, which is seldomly mentioned in these reports, is that repeated sessions of ET prolong the period of chronic aspiration which may lead to irreversible pulmonary sequelae. For that reason many centers recommend only one or two sessions of ET before converting to ST $(8,16,23)$. After all these experiences of endoscopic approach to RTEF, ET is advocated as an alternative to ST. But among the different techniques no definitive technique is proven and accepted as the standard method.

Endoscopic closure methods were used for $\mathrm{H}$ type TEF as well $(16,23)$. Although some successful outcomes were reported, surgical closure of the $\mathrm{H}$ type TEF is still the standard method of treatment (28-30). Finally, apart from RTEF and $\mathrm{H}$ type TEF, ET is also used in treatment of iatrogenic TEF. In a case report, a patient with an iatrogenic TEF secondary to a foreign body ingestion was successfully treated by EC combined with fibrin glue application (10) in a single session.

After having assessed the results of the literature reviews, attention will be given to the papers with relatively high number of patients. In 1999, Bhatnagar et al. reported a small series containing five patients (two with congenital TEF and three with RTEF). They only fulgurated the mucosal lining of the fistula by electrocautery or Nd:YAG laser without any adhesive. And they were successful in two recurrent and one congenital fistula (22).

Tzifa et al. later performed ET in ten patients with 11 fistulae (16). Fistulae were recurrent in seven, $\mathrm{H}$ type in two and traumatic in one patient. During the same period, they treated $182 \mathrm{TEF}$ patients with ST. They destroyed the mucosa using electrocautery or mechanical abrasion. They emphasized that electrocautery stimulates scar formation besides destroying the mucosa. Afterwards they applied histoacryl tissue adhesive in six patients. One patient was excluded from the study and the fistula was successfully closed in nine out of ten fistulae. Six patients have a follow- 

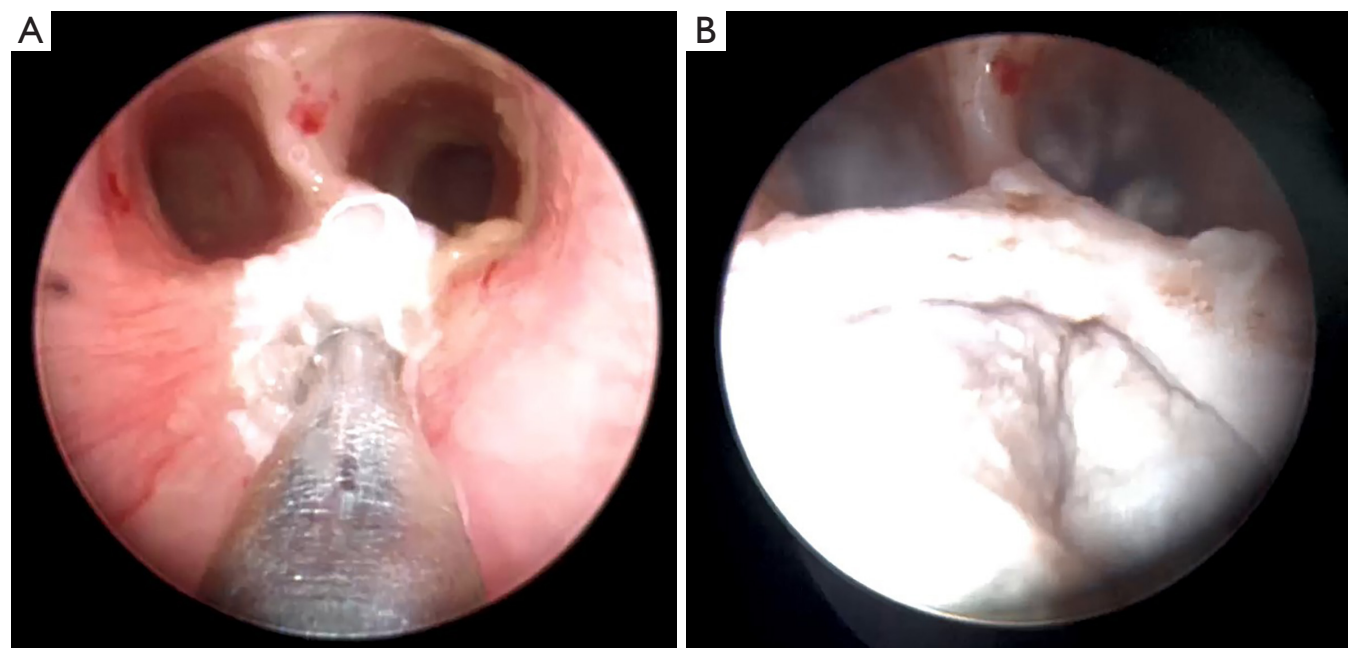

Figure 2 Bronchoscopic views of trichloroacetic acid application. (A) Application of trichloroacetic acid to the fistula; (B) appearance after trichloroacetic acid application.

up period of 3 to 9 years. They concluded that ET is a successful option for closure of both recurrent and $\mathrm{H}$ type TEF and small fistulae are more likely benefit from ET. They also concluded that ST has to be preferred after two sessions of unsuccessful endoscopic session.

In a recent paper about the use of thulium laser for TEF repair, authors tried to close the fistulae by thulium laser only in all but one patient (23). In this single case surgical glue was added to laser fulguration. Study group consisted of 11 patients, 6 recurrent and five $\mathrm{H}$ type TEF. The success rate was $50 \%$ in RTEF patients after a mean of 1.33 sessions and $20 \%$ in H type TEF patients after a mean of one session. Subsequently, they concluded that ET with Thulium laser is appropriate for recurrent TEF, but not for $\mathrm{H}$ type TEF. They also suggest that after one failure, surgical closure of the fistula is indicated, since ET may cause severe complications. Another study on ET of TEF was published by Nazir et al. (11). Three patients had recurrent and six patients had acquired TEF secondary to foreign body and acid ingestion. TEF closed spontaneously in four out of six patients with acquired TEF. Remaining five patients were successfully managed by fulguration with diathermy and fibrin glue application.

In their paper emphasizing long-term follow-up, Willetts et al. performed a postal survey for the long-term follow up of patients who were reported to be managed by ET successfully (31). They found out that only $55 \%$ of these cases remained obliterated in their long-term follow-up. They noticed that all fistula recurrences occurred in the first 12 postoperative months.

Gutiérrez San Román et al. also underlined that longterm follow-up is essential for assessment of ET in RTEF (12). In seven cases with RTEF, they used fibrin glue for the closure of the fistula. In the last four cases, they added diathermy to the management. In a follow-up period of 2 to 11 years in six out of seven patients the fistula was successfully closed after an average of 1.7 sessions. They concluded that the earliest possible diagnosis and treatment after primary anastomosis is an essential factor for success. They also concluded that no complication was observed after a one year follow-up.

In another recent paper with long-term follow-up, Miró et al. reported a series of 14 cases managed by the use of fibrin glue, and the follow-up period was 10 to 20 years (14). In the last 11 cases they additionally used diathermy. After a mean of 2.1 sessions, fistula closure was successful in ten out of 14 patients, and the overall success rate was $71.4 \%$. If divided into two groups, success rates were $72.7 \%$ and $66.6 \%$ in groups treated with diathermy and fibrin glue, and fibrin glue only, respectively. Mean follow-up period for this series was 12.1 years.

TCA, which is a long-standing agent used in otorhinolaryngology practice, is recently used for management of RTEF $(25,26,32) .50 \%$ TCA is applied to the fistula opening three times for 20 seconds in each session via bronchoscopy (26). It provides de-epithelialization and fibrosis and leads to closure of the fistula (Figure 2A,2B). Singhal et al. reported successful chemocauterization with 
TCA in management of TEF for the first time in 2006 (32). Afterwards Sung et al. (26), Lelonge et al. (25), and Lara et al. (33) reported $100 \%$ success rate in three patients, $100 \%$ success rate in 14 patients (12 recurrent TEF and $2 \mathrm{H}$ type TEF) and $83.3 \%$ success rate in 12 patients using TCA alone, respectively. Another point is that minimal morbidity is reported in these small series.

Use of esophagoscopy for a TEF repair is very rarely reported in the literature. Cadena-León et al. were able to close a RTEF using N-butyl-2-cyanocrylate in a single session via esophagoscopy (17). Similarly Yoon et al. reported an effective management of RTEF with Histoacryl glue after mechanical abrasion using a bronchial brush via esophagoscopy (18). They reported esophagoscopy as the proposed approach since there is a pressure variation in the trachea during respiration, which can move the tissue adhesive. Other advantage of esophagoscopic approach is that tracheomalacia, which is associated in many patients, may increase the failure rate of bronchoscopic approach.

There are also some other papers reporting use of different materials and methods to obliterate the TEF. One of these methods is submucosal injection of dextranomer/ hyaluronic acid copolymer after mechanical abrasion of fistula wall mucosa (24). Briganti et al. were able to close the fistula in two out of six patients using this technique. Another case is reported by Gregory et al. They applied Surgisis, which is a biological graft, on the tracheal opening of the TEF after electrocoagulation (21). Cohen-Atsmoni et al., on the other hand, used amplatzer septal occluder to occlude TEF in two patients who have developed TEF due to prolonged entubation (34). The outcome was satisfying in both patients. They concluded that this method is an easy and well tolerated method and is an option for a temporary occlusion of TEF in unstable patients. Lastly, Benatta et al. used metallic stent in a patient with anastomotic stricture and RTEF. The stent was able to dilate the stricture permanently, but the TEF persisted. Afterwards authors placed endoclips at the fistula side and with this methos TEF was successfully closed (35).

In conclusion, ET of RTEF is a technically easy, less invasive, less expensive method of treatment with fewer complications if compared to ST. There is an increased popularity of ET in the literature of TEF repair. Although there are some promising results of use of ET in $\mathrm{H}$ type TEF repair, ST is still the standard method of treatment of this type. Different methods for ET are tried for the management of RTEF, but a standard method with a high success rate is still not specified. Despite these disadvantages, ET is a strong alternative to $\mathrm{ST}$ in the management of RTEF in the future.

\section{Acknowledgments}

Funding: None.

\section{Footnote}

Provenance and Peer Review: This article was commissioned by the Guest Editor (Tutku Soyer) for the series "Tracheoesophageal Fistula" published in Current Challenges in Thoracic Surgery. The article has undergone external peer review.

Conflicts of Interest: The author has completed the ICMJE uniform disclosure form (available at https://ccts. amegroups.com/article/view/10.21037/ccts-21-7/coif). The series "Tracheoesophageal Fistula" was commissioned by the editorial office without any funding or sponsorship. The author has no other conflicts of interest to declare.

Ethical Statement: The author is accountable for all aspects of the work in ensuring that questions related to the accuracy or integrity of any part of the work are appropriately investigated and resolved.

Open Access Statement: This is an Open Access article distributed in accordance with the Creative Commons Attribution-NonCommercial-NoDerivs 4.0 International License (CC BY-NC-ND 4.0), which permits the noncommercial replication and distribution of the article with the strict proviso that no changes or edits are made and the original work is properly cited (including links to both the formal publication through the relevant DOI and the license). See: https://creativecommons.org/licenses/by-nc-nd/4.0/.

\section{References}

1. Ghandour KE, Spitz L, Brereton RJ, et al. Recurrent tracheo-oesophageal fistula: Experience with 24 patients. J Paediatr Child Health 1990;26:89-91.

2. Bruch SW, Hirschl RB, Coran AG. The diagnosis and management of recurrent tracheoesophageal fistulas. J Pediatr Surg 2010;45:337-40.

3. Iacona RV, Saxena AK. Thoracoscopic Repair of Esophageal Atresia with Distal Tracheoesophageal Fistula (Type C): Systematic Review. Surg Laparosc Endosc 
Percutan Tech 2020;30:388-93.

4. Wang J, Zhang M, Pan W, et al. Management of recurrent tracheoesophageal fistula after esophageal atresia and follow-up. Dis Esophagus 2017;30:1-8.

5. Gdanietz K, Wiesner B, Krause I, et al. Tissue-adhesive for sealing of oesophagotracheal fistulae in children (author's transl). Z Erkr Atmungsorgane 1974;141:46-50.

6. Aworanti O, Awadalla S. Management of recurrent tracheoesophageal fistulas: A systematic review. Eur J Pediatr Surg 2014;24:365-75.

7. Richter GT, Ryckman F, Brown RL, et al. Endoscopic management of recurrent tracheoesophageal fistula. J Pediatr Surg 2008;43:238-45.

8. Meier JD, Sulman CG, Almond PS, et al. Endoscopic management of recurrent congenital tracheoesophageal fistula: A review of techniques and results. Int J Pediatr Otorhinolaryngol 2007;71:691-7.

9. Hoelzer DJ, Luft JD. Successful long-term endoscopic closure of a recurrent tracheoesophageal fistula with fibrin glue in a child. Int J Pediatr Otorhinolaryngol 1999;48:259-63.

10. Lao VV, Lustig D, Boseley M, et al. Pediatric ingested foreign body, acquired tracheoesophageal fistula Endoscopic repair with cautery \& fibrin glue (Tisseel): Case report and literature review. J Pediatr Surg Case Reports 2015;3:426-31.

11. Nazir Z, Khan MAM, Qamar J. Recurrent and acquired tracheoesophageal fistulae (TEF)—Minimally invasive management. J Pediatr Surg 2017;52:1688-90.

12. Gutiérrez San Román C, Barrios JE, Lluna J, et al. Long-term assessment of the treatment of recurrent tracheoesophageal fistula with fibrin glue associated with diathermy. J Pediatr Surg 2006;41:1870-3.

13. Wiseman NE. Endoscopic closure of recurrent tracheoesophageal fistula using tisseel. J Pediatr Surg 1995;30:1236-7.

14. Miró I, Gutiérrez C, Carazo E, et al. Fibrin glue treatment associated or not with diathermy for recurrent tracheoesophageal fistula: our results after more than 20 years' experience. Cirugía pediátrica organo Of la Soc Española Cirugía Pediátrica 2020;33:115-8.

15. Brennan M. Fibrin Glue. Blood Rev 1991;5:240-4.

16. Tzifa KT, Maxwell EL, Chait P, et al. Endoscopic treatment of congenital H-Type and recurrent tracheoesophageal fistula with electrocautery and histoacryl glue. Int J Pediatr Otorhinolaryngol 2006;70:925-30.

17. Cadena-León JF, Quimbayo-Wilches DM, RamírezMayans JA, et al. Endoscopic treatment of recurrent tracheoesophageal fistula with a combination of N-butyl-2-cyanocrylate (Histoacryl®) and lipiodol via esophagoscopy in a pediatric patient. Rev Gastroenterol Mex 2016;81:233-5.

18. Yoon JH, Lee HL, Lee OY, et al. Endoscopic treatment of recurrent congenital tracheoesophageal fistula with Histoacryl glue via the esophagus. Gastrointest Endosc 2009;69:1394-6.

19. López J, Rodriguez K, Targarona EM, et al. Systematic Review of Cyanoacrylate Embolization for Refractory Gastrointestinal Fistulae: A Promising Therapy. Surg Innov 2015;22:88-96.

20. Lal DR, Oldham K. Recurrent tracheoesophageal fistula. Eur J Pediatr Surg 2013;23:214-8.

21. Gregory S, Chun RH, Parakininkas D, et al. Endoscopic esophageal and tracheal cauterization for closure of recurrent tracheoesophageal fistula: A case report and review of the literature. Int J Pediatr Otorhinolaryngol 2017;98:158-61.

22. Bhatnagar V, Lal R, Sriniwas M, et al. Endoscopic treatment of tracheoesophageal fistula using electrocautery and the Nd:YAG laser. J Pediatr Surg 1999;34:464-7.

23. Luscan R, Simon F, Khen Dunlop N, et al. Thulium LASER for endoscopic closure of tracheoesophageal fistula in esophageal atresia's spectrum: An appropriate tool? J Pediatr Surg 2020;S0022-3468(20)30753-3.

24. Briganti V, Coletta R, Giannino G, et al. Usefulness of dextranomer/hyaluronic acid copolymer in bronchoscopic treatment of recurrent tracheoesophageal fistula in children. Int J Pediatr Otorhinolaryngol 2011;75:1191-4.

25. Lelonge $Y$, Varlet F, Varela $\mathrm{P}$, et al. Chemocauterization with trichloroacetic acid in congenital and recurrent tracheoesophageal fistula: a minimally invasive treatment. Surg Endosc 2016;30:1662-6.

26. Sung MW, Chang H, Hah JH, et al. Endoscopic management of recurrent tracheoesophageal fistula with trichloroacetic acid chemocauterization: A preliminary report. J Pediatr Surg 2008;43:2124-7.

27. Keckler SJ, St Peter SD, Calkins CM, et al. Occlusion of a recurrent tracheoesophageal fistula with surgisis. J Laparoendosc Adv Surg Tech A 2008;18:465-8.

28. Al-Salem AH, Al Mohaidly M, Al-Buainain HMH, et al. Congenital H-type tracheoesophageal fistula: a national multicenter study. Pediatr Surg Int 2016;32:487-91.

29. Fallon SC, Langer JC, St. Peter SD, et al. Congenital H-type tracheoesophageal fistula: A multicenter review of outcomes in a rare disease. J Pediatr Surg 2017;52:1711-4.

30. Parolini F, Morandi A, Macchini F, et al. Cervical/ 
thoracotomic/thoracoscopic approaches for H-type congenital tracheo-esophageal fistula: A systematic review. Int J Pediatr Otorhinolaryngol 2014;78:985-9.

31. Willetts IE, Dudley NE, Tam PKH. Endoscopic treatment of recurrent tracheo-oesophageal fistulae: Long-term results. Pediatr Surg Int 1998;13:256-8.

32. Singhal SK, Virk RS, Dass A, et al. Tracheoesophageal fistula: New option in management. Indian J Otolaryngol Head Neck Surg 2006;58:300-2.

33. Lara DPR, Riveros LVM, Pineda LRS, et al. DOZ047.110: Recurrent tracheoesophageal fistula tracheoscopic

doi: $10.21037 /$ ccts-21-7

Cite this article as: Kiyan G. Endoscopic treatment of tracheoesophageal fistula. Curr Chall Thorac Surg 2022;4:28. chemocauterization with trichloroacetic acid. Dis Esophagus 2019;32:35-6.

34. Cohen-Atsmoni S, Tamir A, Avni Y, et al. Endoscopic occlusion of tracheoesophageal fistula in ventilated patients using an amplatzer septal occluder. Indian J Otolaryngol Head Neck Surg 2015;67:196-9.

35. Benatta MA, Benaired A, Khelifaoui A. Endoscopic stenting and clipping for anastomotic stricture and persistent tracheoesophageal fistula after surgical repair of esophageal atresia in an infant. Case Rep Med 2014;2014:738981. 